\title{
A questão nacional na América Latina: o árduo caminho da atitude comparativa
}

\section{The national question in Latin America: the rough road of comparative approaches}

\author{
Claudia Wasserman \\ Professora associada do Programa de Pós-graduação em História/Universidade Federal \\ do Rio Grande do Sul; pesquisadora do CNPq. \\ claudia.wasserman@ufrgs.br
}

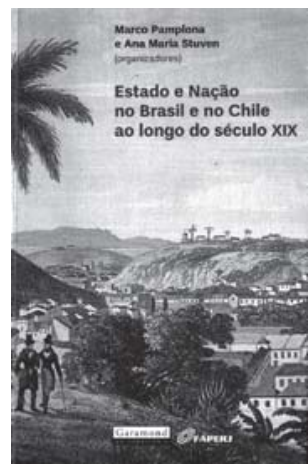

PAMPLONA, Marco; STUVEN, Ana Maria (Org.). Estado e nação no Brasil e no Chile ao longo do século XIX. Rio de Janeiro: Garamond, 2010. 368p.

\begin{abstract}
A ausência de fronteiras, os idiomas diferentes e as dificuldades de intercâmbio cultural não impediram que, ao longo da história republicana, Chile e Brasil estabelecessem laços acadêmicos que marcaram a produção intelectual dos dois países. O Chile foi um dos destinos dos intelectuais brasileiros, exilados nos anos 1960 e 1970. A Universidade de Concepción e o Centro de Estudos Socioeconômicos (Ceso), da Faculdade de Economia da Universidade do Chile foram algumas das instituições que acolheram esses brasileiros, entre eles Fernando Henrique Cardoso, Theotônio dos Santos, Vânia Bambirra, Ruy Mauro Marini, Darcy Ribeiro e Maria da Conceição Tavares. Chilenos e brasileiros trabalharam juntos na academia, estabelecendo intensa fraternidade profissional, fundando revistas científicas, promovendo encontros, publicando livros e artigos que exerceram influência não desprezível em toda a intelectualidade subcontinental.
\end{abstract}

Chile e Brasil foram igualmente os 'eixos geográficos' da gestação de teorias originais para compreensão das sociedades periféricas, sobretudo da América Latina. A contribuição de Fernando Henrique Cardoso e Enzo Falletto, a partir da publicação do livro Dependência e desenvolvimento na América Latina, em 1970, por exemplo, não pode ser desconsiderada. Outro antecedente do relacionamento entre intelectuais chilenos e brasileiros foi a criação da Comissão Econômica Para a América Latina e o Caribe (Cepal), em 1948, com sede em Santiago e composta por economistas e sociólogos predominantemente brasileiros e chilenos, entre os quais se destacaram Celso Furtado e Aníbal Pinto. Nesse sentido, a iniciativa de cooperação historiográfica, acadêmica e intelectual entre os dois países não se iniciou com a reunião dos autores brasileiros e chilenos no livro coordenado por Marco Pamplona e Ana Maria Stuven. A publicação de Estado e nação no Brasil e no Chile ao longo do século XIX constitui, assim mesmo, um empreendimento importante, sobretudo porque trata de matéria pouco abordada: a formação dos Estados, das nações e das nacionalidades nos dois países. 
O volume, dividido em quatro partes, evidencia temas como as independências, a construção da identidade nacional através de guerras do século XIX (Guerra do Paraguai e Guerra do Pacífico), a produção de símbolos nacionais por intermédio da pintura histórica e da fotografia, e problemas ligados à construção da cidadania e inclusão social.

Na primeira parte, "Desafio da construção de Estados e nações modernas", os artigos de Márcia Regina Berbel e Lucrecia Enriquez traçam os passos de Brasil e Chile no início do século XIX, quando as metrópoles ibéricas sofreram a invasão napoleônica. Procuram analisar os múltiplos efeitos desse processo no âmbito colonial, que terminaram por conduzir os dois países, e quase toda América Latina, aos processos de independência. Berbel julga que a tentativa das Cortes portuguesas e espanholas em afirmar a soberania diante da invasão napoleônica resultou na formação de "espaços parlamentares" e "demandas por autonomia" (p.30), no âmbito colonial. A pesquisa revela a atividade parlamentar da representação colonial nas Cortes e pondera sobre o "amadurecimento de um projeto autonomista" (p.37), resultando em um olhar do processo de independência que parte da metrópole.

Lucrecia Enríquez trata da independência chilena. Considera que as Reformas Bourbônicas, os movimentos populares, as guerras entre facções criollas, a ambição de poder dos militares americanos foram mais decisivos para o desfecho do processo emancipatório do que a representação colonial nas Cortes. No intuito de comparar o caso brasileiro com o chileno, Enríquez se refere à manutenção da monarquia no Brasil. A conclusão ligeira sobre a ocorrência tardia de debates a respeito de república, unitarismo ou federalismo faz o leitor pensar que o centralismo imposto pela monarquia brasileira era consensual, esquecendo-se a quantidade e a intensidade das revoltas contra o poder central e contra o próprio poder monárquico que ocorreu no país.

A segunda parte, "Três olhares sobre as identidades nacionais", traz artigos de Ilmar Rohloff de Mattos, Ricardo Salles e Carmen McEvoy. Os dois últimos autores produzem excelentes sínteses de como as guerras do Paraguai e do Pacífico produziram efeitos importantes para a sedimentação da identidade nacional brasileira e chilena, respectivamente. Enquanto Salles orienta sua pesquisa para o impacto da Guerra do Paraguai e do movimento abolicionista na questão nacional, McEvoy relata magnificamente a saga de Benjamin Vicuña Mackenna, colecionador, político e historiador chileno, que escreveu sobre a Guerra do Pacífico a partir da documentação sonegada do Peru. McEvoy revela como "a degradação do povo inimigo e a mutilação de sua memória histórica tiveram a ver diretamente com a consolidação de uma identidade nacional que ao afirmar a própria superioridade, justificava sua missão civilizadora" (p.160). A dicotomia entre civilização e barbárie, a primeira atribuída aos chilenos e a segunda, aos peruanos, foi característica do pensamento da época, cujo maior expoente era o argentino Domingo Faustino Sarmiento, exilado no Chile durante a década de 1840. É provável que Vicuña Mackenna tenha recebido influência do livro Facundo o Civilización y barbarie, publicado em 1845.

Ilmar Mattos, por sua parte, reflete em nove notas sobre a "proposição amplamente difundida de uma singularidade" (p.99) da experiência histórica brasileira no século XIX, a monarquia. Nesse artigo, as "diferenças que identificam o Império do Brasil" (p.99) são tratadas consistentemente e, sem mencionar os demais países do subcontinente, Mattos 
alcança um resultado eficaz no tratamento singular da história brasileira. Ressalta a ambígua convivência do 'novo' país com as heranças dos colonizadores e atribui à 'transmigração' da família real portuguesa para o Brasil o papel de materialização da nossa singularidade.

Na parte três do volume, "A produção e divulgação de símbolos nacionais", aborda esses elementos, sobretudo a pintura histórica e a fotografia, como construtos imagéticos da identidade nacional. Maria Ligia Coelho Prado analisa a obra do pintor chileno Pedro Subercaseaux e, ao mesmo tempo, compara-o com outros artistas latino-americanos - o brasileiro Pedro Américo e o uruguaio Juan Manuel Blanes -, dedicados igualmente à pintura histórica na mesma época e que compartilharam temáticas como a independência e a primeira missa. Ao identificar nas obras dos artistas a intenção de afirmar símbolos nacionais por intermédio do retrato de imagens históricas, a autora observa como os personagens são representados e o lugar que ocupam nelas.

$\mathrm{O}$ artigo de Fernando Purcel ajuda a explicar por que a fotografia, mais do que a pintura histórica, teve papel decisivo na conformação do imaginário nacional e na constituição do que Anderson (1989, p.15 e ss) denomina comunidade imaginada. No Chile, a expansão geográfica do país, ligada à incorporação de novos territórios, foi o elemento central da construção da identidade nacional. Na mesma direção, o episódio histórico que forneceu significado a essa presunção foi a Guerra do Pacífico, mais do que a guerra de independência ou a celebração da primeira missa. Nesse sentido, o apoio do Estado chileno à arte fotográfica foi crescente e intenso: "houve um esforço das elites governantes para dar significado ao território, com a clara intenção de gerar uma identidade nacional associada à geografia do país" (p.215). Nas abundantes fotografias da Guerra do Pacífico, a bandeira chilena cravada em território inimigo constituía símbolo da identidade nacional, relacionada ao espaço geográfico. Purcel, assim como McEvoy, associa a valorização de retratos acerca da incorporação territorial, do povoamento de novas áreas e do progresso urbano e industrial com as pretensões civilizatórias do Estado chileno. O artigo ressalta aquele aspecto teórico, mencionado por Gellner (1993, p.89), "culturalmente criativo, imaginativo, positivamente inventivo" no processo de constituição das nações.

O artigo de Joaquín Fermandois e Mariana Perry chama a atenção para o fator internacional na construção de uma consciência nacional, demonstrando como o Chile se posicionava em relação aos poderosos vizinhos Argentina e Brasil. Revelam documentos importantes na relação entre os três países, em que o Brasil aparece como um ponto de equilíbrio na tradicional rivalidade estratégica entre Chile e Argentina.

Na última parte do livro, "Ideias, práticas e relações para uma nação moderna", Eduardo Cavieres F. e Marcelo Mardones F. se dedicam ao estudo dos 'empresários' no século XIX, no Brasil e no Chile. O título dessa parte do livro ajuda a explicar por que os 'empresários' podem aparecer como o 'cimento' da constituição da nação. O texto visa identificar os agentes econômicos que em cada país, ao longo do século XIX, deram origem e forneceram as características do 'empresariado nacional'. O assunto remete às atividades econômicas predominantes, que fornecem significado à formação de um mercado interno. Ainda que sejam 'voltadas para fora', tais atividades - identificadas no comércio, na mineração e na cafeicultura - terminam por unificar o Estado em torno de um projeto de desenvolvimento. Nesse artigo, a comparação entre Chile e Brasil é eficaz, pois produz termos de semelhanças 
e diferenças que podem ser aferidos pelas características comuns a ambos os casos e pelas peculiaridades. Nos dois países, a economia primário-exportadora conduz ao crescimento industrial e ao surgimento de um grupo de empresários "renovadores do tecido econômico e social" (p.276). Os autores analisam, sobretudo, as relações contraditórias entre esse novo setor industrial e as oligarquias primário-exportadoras, pólos dinâmicos da acumulação capitalista nos dois países. E abordam as iniciativas associativas desses novos empresários nacionais.

O artigo de Maria Tereza Chaves de Mello expõe a dicotomia entre as visões de nação em José de Alencar, de um lado, e em Joaquim Nabuco, de outro. O primeiro seria portador de uma visão romântica de nação, a partir da centralidade do indígena na cultura brasileira, exposta pela peça de teatro "O jesuíta", que estreou em 1875 e gerou uma das polêmicas intelectuais do século XIX. Joaquim Nabuco fez a crítica do espetáculo, em O Globo, procurando explicar o motivo do fracasso de público desde a estreia da peça. A geração de Nabuco contrapunha o romantismo de Alencar ao cientificismo, ao positivismo e ao evolucionismo. Interessados nas campanhas republicana e abolicionista, os intelectuais dos anos 1870 opunham à idealização de Alencar, de conformação de um Estado nacional monárquico e unitário em um país marcadamente rural e com uma concepção de tempo que "não escoava, era a repetição do mesmo" (p.320). A concepção que se opunha era a republicana, dotada de uma temporalidade que procurava romper com o passado colonial. Sob esse ponto de vista, o mestiço apresentava-se como criador da cultura original brasileira, em oposição ao índio que era o habitante primitivo, exaltado pelos românticos.

O último artigo, de Ana Maria Stuven, demarca a transição da nação construída pelo alto, o que Hobsbawn (1990, cap.3) chamou de perspectiva governamental, para a fase em que os grupos sociais populares são "capturados pela consciência nacional" (p.21). O artigo evidencia a tese de que a "consciência nacional se desenvolve desigualmente entre os grupos e regiões sociais de um país" (p.21). Stuven refere-se aos trabalhadores representados por Francisco Bilbao, por exemplo. O texto indica a década de 1840 como a época de consolidação da nação chilena, por intervenção da "Geração de 1842 e dos exilados argentinos" (p.335), o que reforça a hipótese de influência de Sarmiento na obra de Vicuña Mackenna. O epílogo do livro não poderia ser diferente, aborda a questão social do final do século XIX, que se torna parte do problema da constituição das nações e da construção das identidades nacionais em toda a América Latina.

O que sobressai em Estado e nação no Brasil e no Chile ao longo do século XIX é a perspectiva de converter assuntos que poderiam ter uma análise apenas nacional, em uma interpretação cuja abrangência ultrapassa esses limites. A comparação pretendeu ser adotada como metodologia capaz de romper com a singularidade dos casos. Ao mesmo tempo, a seleção de uma temática definida - formação dos Estados nacionais e constituição das identidades permitiu a abordagem de vários temas correlatos nos dois países, todos conectados ao assunto principal, fornecendo consistência à obra. No entanto, apesar do esforço orientado para entender a questão nacional comum aos dois países latino-americanos, a maior parte dos artigos conseguiu apenas aproximar as histórias nacionais, justapondo-as sem conectálas organicamente ou compará-las com maior consistência. A consistência na análise comparativa depende, em grande medida, da excelência no desenvolvimento das histórias 
singulares e do estudo de temas pontuais em cada uma das regiões que compõem o subcontinente latino-americano, tarefa que o livro se propõe e cujos resultados são bastante positivos. Por isso, contribuir para o desenvolvimento das histórias nacionais está entre as prioridades do historiador da América Latina, mesmo que o campo de conhecimento história latino-americana - pretenda ultrapassar os limites do Estado-nação.

\section{REFERÊNCIAS}

ANDERSON, Benedict.

Nação e consciência nacional. Ática: São Paulo. 1989.

CARDOSO, Fernado Henrique; FALETTO,

Enzo.

Dependência e desenvolvimento na América Latina. 6.ed. Rio de Janeiro: Zahar. 1981.

GELLNER, Ernest.

Nações e nacionalismos: trajectos. Gradiva: Lisboa. 1993.
HOBSBAWM, Eric J.

Nações e nacionalismos desde 1780. Rio de Janeiro: Paz e Terra. 1990.

SARMIENTO, Domingo Faustino.

Facundo. Porto Alegre: EdUFRGS. 1996.

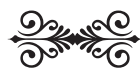

